\title{
THE NEW BREED OF TRADE MARKS: SOUNDS, SMELLS AND TASTES
}

\author{
Jacey K McGrath*
}

Sounds, smells and tastes can now be registered as trade marks in New Zealand under the Trade Marks Act 1953. These novel types of signs raise concerns about their ability to act as effectively as the more traditional word and design trade marks. Consumers will have to utilise less perceptive senses in order to comprehend these marks, and may not be able to rely on them to distinguish products at the point of sale. The inherent intangibility of these marks may also have implications for determining questions of similarity and the likelihood of confusion in infringement actions.

Unlike the more traditional trade marks, sounds, smells and tastes are usually intrinsic features of products. Such characteristics should not be registrable as trade marks because they are not sufficiently separate from the underlying goods and would allow a trader to have a monopoly over their production. The rationale behind trade mark protection must not be lost sight of in the desire to shield innovative traders who utilise exciting signs to market their products.

\section{INTRODUCTION}

The Trade Marks Amendment Act $1999^{1}$ emerged from the Intellectual Property Right Acts Amendment Bill 1998, along with several other legislative amendments. Rather than seeking to effect any wide-ranging reforms, the Bill simply made a few modifications to our intellectual property laws so as to ensure that New Zealand complies with its obligations under the World Trade Organization. ${ }^{2}$

* This paper was submitted in fulfilment of the LLB(Hons) requirements at Victoria University in 2000.

1 This Act came into force on 14 October 1999.

2 (5 October 1999) 580 NZPD 19602. 
A small, and seemingly unremarkable, change made by the Act was the specific provision allowing sounds, smells and tastes to be registrable as trade marks. At first glance this seems to simply demonstrate a modern understanding of the diverse methods employed by manufacturers and marketers in the differentiation and promotion of their products in today's competitive marketplace. As such, it appears that these devices serve the purpose of distinguishing products for the benefit of competition, and thus should be registrable as trade marks. It is arguable that they amount to little more than a difference in form from the more common word and design marks.

The rationale underlying the conferral of legislative rights to owners of registered trade marks needs to be analysed before one can conclude that sounds, smells and tastes can properly fit within the policy framework. Several issues arise in relation to the registration of such marks that may not have been identified by the Legislature.

The registration of a trade mark under the Act provides its proprietor with a potentially indefinite right to the exclusive use of the mark in relation to the class or classes of goods or services in respect of which it is registered. Such a right can be extremely valuable to a manufacturer if the trade mark is appealing to, and sought after by, consumers. This is especially true in the context of the modern prevalence of branding, where consumers often select goods or services primarily for the associated label. One must therefore be careful about extending the rights conferred by the trade mark registration system to product features that do not fully comply with the policy underlying trade marks.

Care should be taken to ensure that the law of trade marks is not expanded so as to provide protection that is analogous to that conferred by copyright or patents. The branches of intellectual property from which trade marks and copyright stem are fundamentally dissimilar. A sound, smell or taste should not be registrable as a trade mark if it is tantamount to the whole product, rather than just a label attaching to the product. Protection is afforded to trade marks in order to aid competition, not to create monopoly rights.

In order to be registered as a trade mark, a sign must be capable of being represented graphically and capable of distinguishing the goods or services of one person from those of another. ${ }^{3}$ A novel issue arises in respect of sounds, smells and tastes because it is not clear if they can be unambiguously represented for the purpose of graphic representation. No such

3 Trade Marks Act 1953, s 2(1) "trade mark". 
problems have arisen in the context of the more traditional, visually perceptible signs, as they can be clearly depicted by words or a drawing.

It is also uncertain if sounds, smells and tastes are even capable of distinguishing products. Such signs may not be inherently distinctive enough to function as marks for consumers to perceive and rely on when making purchasing decisions. Unlike the more traditional trade marks, the perception of sounds, smells and tastes depends on senses other than sight, which consumers are unaccustomed to utilising in their recognition of goods.

Similar issues may develop in the context of determining if a sound, scent or taste mark has been infringed. If these marks are graphically represented on the trade marks register by a written description, the necessary breadth of the explanation may catch several other marks, thus causing them to be legally identical. The intangible nature of these signs also means that it will be more difficult to objectively determine the similarity of, or the likelihood of confusion from, a competitor's mark.

It remains to be seen how the Intellectual Property Office of New Zealand (IPONZ) and the courts will resolve the issues raised by the registration of these new types of trade marks. A thorough analysis of the policy behind trade mark law, and the formation of workable criteria for resolving registration and infringement issues, need to be made before sounds, smells or tastes are registered as trade marks.

\section{TRADE MARKS}

Trade marks have been attached to goods for various purposes since pre-historic times. ${ }^{4}$ The production marks commonly used in the twelfth and thirteenth centuries acted as a form of medieval consumer protection. The guilds that supervised each trade required traders to attach production marks to goods as a symbol of quality workmanship. These marks represented the producer, rather than the product, as all goods were assured to be of the same standard. The motivation for this protection was to prevent the injury done to consumers and producers alike by counterfeit goods. ${ }^{5}$ However, the cloth industry demonstrated a more modern use of the trade mark, as products were known for their individual excellence. Trade symbols had pre-sale significance to consumers because they identified the quality of the

4 C D G Pickering Trade Marks in Theory and Practice (Hart Publishing, Oxford, 1998) 36.

5 Pickering, above n 4, 56. 
products. This concept of collective goodwill represents the origin of what is today recognised as a trade mark. ${ }^{6}$

Trade marks gained in importance as a link between the producer and the consumer in the seventeenth century, where the advent of mass production meant that goods were marketed nationally. The physical separation of the producer from the consumer resulted in the trade mark becoming established as an asset of commercial value. ${ }^{7}$

Today, trade marks no longer primarily serve to denote the source of goods. The actual producer is less relevant because of the current prevalence of trade mark licensing. ${ }^{8}$ However, a trade mark can indicate a connection between the goods and the source from which previously satisfactory goods emanated, rather than from a particular, known source. A trade mark can therefore perform the function of a guarantee, by signifying to consumers that the product is of a consistent quality. This, in turn, gives the producer an economic incentive to maintain the brand at a particular standard. ${ }^{9}$

The most basic function of a contemporary trade mark is to differentiate a product from others in the marketplace. ${ }^{10}$ The practice of branding involves the development of appealing and distinctive product attributes to present to consumers. A trade mark is usually a fundamental component of a brand, as it can create an identity for a brand through advertising. ${ }^{11}$

Trade marks provide a source of information about the characteristics of a product. ${ }^{12}$ They can do this by consisting of symbols that are meaningful and relevant to a consumer's purchasing decision, or by providing a link between the trade mark and the consumer's past

10 Pickering, above n 4, 45.

11 This is the advertising function of a trade mark. See Pickering, above n 4, 47.

12 Pickering, above n 4, 86. 
experience of the product or its advertising. A consumer's search costs are therefore reduced by the identification of a trade mark. ${ }^{13}$

The modern concept of trade marks as a method of differentiating products encourages producers to invest substantially in branding. ${ }^{14}$ The wealth of products available in the marketplace makes the success of one largely depend on appearing more desirable than its alternatives. Constant investment in advertising helps to keep a product in the front of consumers' minds, thus making it the most obvious choice.

In this way trade mark protection appears similar to copyright and patents, in that it protects the investment in making a brand attractive to consumers. However, the rationale behind trade marks is fundamentally different from these other intellectual property rights. Copyright "protects both the highest forms of intellectual and artistic endeavour and yet the most banal industrial or engineering drawings ... [it] aims to protect the expression of the human mind". ${ }^{15}$ By contrast, a trade mark is not protected for its own intrinsic worth, but for the intangible values surrounding the product and attaching to the mark. Trade marks consequently require continued investment and management to add value. ${ }^{16}$ While copyright confers a proprietary right in a creation, such as a painting or musical work, the registration of a trade mark only grants the right to its use in relation to the class of product for which it is registered.

A trade mark can be protected today by registering it under the Trade Marks Act 1953, by which the sole right to use the mark in respect of the goods or services is granted. Alternatively, a trader can bring an action in the tort of passing off against an unauthorised user of its mark. ${ }^{17}$

13 Pickering, above n $4,88$.

14 Pickering, above n 4, 55.

15 A Brown \& A Grant The Law of Intellectual Property in New Zealand: An Exposition of the New Zealand Law Relating to Trade Marks, Passing Off, Copyright, Registered Designs, Patents, Trade Secrets and the Fair Trading Act 1986 (Butterworths, Wellington, 1989) 223.

16 Pickering, above $\mathrm{n} 4,116$.

17 However, the modern law of passing off is of a fundamentally different basis than straightforward trade mark protection. "[T]he essence of [passing off] is the protection of a trader's 'goodwill' from tortious interference through another trader's misrepresentation." Pickering, above n 4, 29. 


\section{THE TRADE MARKS AMENDMENT ACT 1999}

\section{A The Changes Made}

The main changes made by the Trade Marks Amendment Act 1999 were providing for the registration of collective trade marks and amending the definition of "convention country" in the Trade Marks Act 1953. ${ }^{18}$ The amendment also enlarged the scope of signs that could be registered as trade marks.

Traditional trade marks, such as names, words, letters and devices, have always been able to be protected under New Zealand's trade mark legislation. The Trade Marks Amendment Act 1994 increased the scope of what could be registered as a trade mark, by replacing the definition of "mark" with "sign"19 and amending the definition of "trade mark". ${ }^{20}$ Less traditional trade marks, such as container shapes and colour combinations, could consequently be registered under the legislation. ${ }^{21}$

The Trade Marks Amendment Act 1999 further amended the definition of "sign" as follows: ${ }^{22}$

"Sign" includes -

A brand, colour, device, heading, label, letter, name, numeral, signature, smell, sound, taste, ticket

or word; and

Any combination of signs.

This change expressly includes sounds, smells and tastes as signs that can be registered as trade marks. Such signs are registrable if they qualify as trade marks, by being capable of being

18 (6 May 1998) 567 NZPD 8298.

19 "Sign" was given an inclusive definition.

20 "Trade mark" now means "except in relation to a certification trade mark, any sign or any combination of signs, capable of being represented graphically and capable of distinguishing the goods or services of one person from those of another person, and means, in relation to a certification trade mark, a sign registered or deemed to have been registered on an application under section 47 of this Act". Trade Marks Act 1953, s 2(1).

21 A Potter "Trade Marks Amendment Act 1999: It's Not as Simple as it Looks, Sounds, Smells or Tastes" (2000) 2 NZIPJ 225, 225.

22 Trade Marks Amendment Act 1999, s 2(1). 
represented graphically and capable of distinguishing the goods or services of one person from those of another person. ${ }^{23}$

The 1994 amendment, however, was generally believed to enable sounds and smells to constitute signs registrable as trade marks, due to the inclusive definition of "sign". ${ }^{24}$ Indeed, the Unilever "squeak" sound ${ }^{25}$ and "The Warehouse" jingle ${ }^{26}$ were registered as trade marks in 1995, the "Greensleeves" arrangement was registered in 1998, 27 and a piece of instrumental music was registered in early 1999. ${ }^{28}$ In addition, The Boots Company PLC applied in 1995 for the registration of a trade mark consisting of the smell of cinnamon as applied to pharmaceutical preparations and substances. ${ }^{29}$

\section{$B$ The Purpose of the Changes}

The impetus for the enactment of the Trade Marks Amendment Act 1999 is explained in the commentary to the Intellectual Property Right Acts Amendment Bill 1998 as reported from the Commerce Committee. ${ }^{30}$ The commentary describes the submission jointly made by the New Zealand Institute of Patent Attorneys (NZIPA) and the New Zealand Group of the International Association for the Protection of Industrial Property (AIPPI): ${ }^{31}$

23 Trade Marks Act 1953, s 2(1) definition of "trade mark".

24 Potter, above n 21, 226.

25 Trade mark number 247094, filed 23 March 1995, in respect of hand dishwashing products, to Unilever PLC.

26 Trade mark number 252035, filed 7 August 1995, in respect of schedule class 4/42 (wholesaling, retailing, or design services, or advisory or consultancy services, with respect to consumer goods), to The Warehouse Limited.

27 Trade mark number 289083, filed 27 February 1998, in respect of schedule class 4/35 (retail and wholesale services in relation to dairy products, ice cream and frozen confectionery), to The New Zealand Co-operative Dairy Company Ltd.

28 Trade mark numbers 304552 and 304553, filed 1 February 1999, in respect of classes 4/9 and 4/42, to Dolby Laboratories Licensing Corporation.

29 Trade mark number 248231. Although this application was abandoned by the applicant on 19 April 1995, the initial attempt to register this smell as a trade mark confirms the general belief that sounds and smells were able to be registered after the Trade Marks Amendment Act 1994, rather than just after the 1999 Act.

30 Potter, above n 21, 226.

31 Pages ii to iii. 
The NZIPA submitted that the definition of "sign" should expressly include sound and smell. The definition in the Trade Marks Act 1953 does not expressly exclude sounds and smells. We were advised that an amendment to the definition of trade marks in 1994 was not intended to exclude sound and smell. Thus, we recommend sound and smell be expressly included in the definition of "sign" in clause 7. We also recommend that "taste" be included in the definition of "sign".

The whole stimulus behind the Intellectual Property Right Acts Amendment Bill 1998 was to "ensure than New Zealand fully compl[ies] with [its] obligation[s] under the World Trade Organization Agreement on Trade-related Aspects of Intellectual Property Rights, known as the 'TRIPs' agreement." ${ }^{32}$ Article 15 of TRIPs contains the basic rule regarding the scope of trade marks. Any sign, or combination of signs, capable of distinguishing the goods or service of one undertaking from those of other undertakings, shall be capable of constituting a trade mark. Members may require as a condition of registration that signs be visually perceptible.

TRIPs does not require that sounds, smells and tastes be included in the legislation of Member States as signs capable of constituting a trade mark. However, if they are deemed to be signs capable of distinguishing the products of one trader from the products of others, it is certainly arguable that sounds, smells and tastes should be registrable as trade marks. This argument is strengthened by the fact that the New Zealand Legislature did not opt to include the condition that signs be visually perceptible. The Act instead imposes the less restrictive requirement that signs be capable of graphic representation. Indeed, the basis for NZIPA's submission on specifically including sounds and smells in the definition of "sign" was that sounds and smells "are both signs which are capable of being represented graphically and which are capable of distinguishing the goods or services [of] one trader from those of another." 33

A second reason given for the inclusion of sounds and smells was the desirability of according with international practice. It is significant that sounds and smells are registrable as trade marks in several other countries. ${ }^{34}$ It is unclear, however, why the Commerce Select Committee sought to include tastes as signs under the Act, as no submissions were received on this issue. The Committee perhaps simply assumed that tastes can also be signs capable of distinguishing goods or services.

32 (6 May 1998) 567 NZPD 8298.

33 Submission No 1, page 6, paragraph 4.2-2.

34 Submission No 1, page 6, paragraph 4.2-3. 
The New Zealand trade mark registration law has previously fallen behind the developments in other countries. ${ }^{35}$ Unlike the advanced registration systems existing in civil law countries, such as France, common law countries, such as New Zealand, formerly dealt with deficiencies in their trade mark registration systems by affording protection under the tort of passing off. While this may have meant that there was no pressing need for a new system domestically, the alignment of our trade mark registration system with those of our trading partners was certainly perceived as desirable, particularly in light of TRIPs.

The 1999 amendment was deemed to "ensure that legislation is updated to reflect the dynamic world that we are now part of ... in terms of the diversity of intellectual property rights". ${ }^{36}$ Pansy Wong MP stated that she was "looking forward to the world that will now take even more flair in creating unique fragrances, sounds, sights, and tastes [as] [t]hat makes the world a lot more interesting." 37

However, one must remember that the policy of trade marks is not to encourage the creation of interesting signs. ${ }^{38}$ Trade marks are not protected for their own sake, but for their use in relation to the goods or services for which they are registered. The trade mark is a creature of commerce, not art, and the sole right to its use is granted in the interests of efficiency and competition. ${ }^{39}$ This amendment recognises that marketers are employing more exciting methods for advertising and distinguishing their products. Catchy jingles and niche marketing are becoming more and more prevalent. Increased and more diverse competition may indeed be encouraged by the amendment, which will benefit consumers in this global marketplace.

\section{CAN SOUNDS, SMELLS AND TASTES FUNCTION AS TRADE MARKS?}

The most basic function of a trade mark is to distinguish goods. ${ }^{40}$ Sound, smell and taste marks must therefore be perceived by consumers to be sufficiently distinctive to make the associated product stand out from its substitutes. However, the performance of this function is

35 Information obtained from R J T Ellis, Baldwin Shelston Waters, 10 July 2000.

36 (5 October 1999) 580 NZPD 19609.

37 (5 October 1999) 580 NZPD 19610.

38 Pickering, above n 4, 157.

39 Pickering, above n 4, 154.

40 Pickering, above n 4, 45. 
not enough for such a sign to truly act as a trade mark. The sound, smell or taste must also distinguish the product by associating it with its origin in the minds of consumers. These new types of registrable signs therefore raise issues concerning both their inherent distinctiveness and their ability to create an association with the product's source.

\section{A The Perceptiveness of the Senses of Hearing, Smell and Taste}

Allowing the senses of hearing, smell and taste to be utilised in perceiving trade marks is quite a novelty. It raises the question of whether or not these senses are sharp enough to remember and distinguish signs consisting of sound, smell and taste. The more traditional trade marks are composed of words or designs, which are identified by the sense of sight. Amidst the huge range of products available in the marketplace, a product can often only stand out from its many alternatives by the use of eye-catching packaging. Consumers have become adept at comprehending the visual aspects of a product's trade dress, in order to recognise it swiftly in the future. Will we be as proficient at differentiating between products by the use of our other senses?

\section{Hearing}

Human hearing is a very perceptive sense. This is probably due to the fact that hearing is "vital to human communication because it is central in social interactions and in transmitting knowledge." 41 The perceptual qualities one notices from a sound are its pitch, loudness, timbre and direction. ${ }^{42}$ A lot of information is gleaned from the language of others: ${ }^{43}$

The mystery, then, is that we can perceive speech quickly and with a generally high degree of accuracy when there are so many potential words to recognize, when those words are pronounced with such variability, and when there are usually no clear boundaries between the individual words ... speech perception is so efficient.

The significance of hearing in our lives is further evidenced by the human appreciation of music. Music has often been described as the "language of the emotions" because of the effect it can have on people. "Music mimics experience rather than symbolizes it, as language does. It carefully replicates the temporal patterns of interior feeling, surging in pitch or volume as

41 M W Matlin Sensation and Perception (2 ed, Allyn \& Bacon Inc., Massachusetts, 1988) 266.

42 Matlin, above $n$ 41, 283.

43 Matlin, above $n$ 41, 318. 
they surge, ebbing as they ebb."44 Music has even been used as an effective treatment for the symptoms of Parkinson's disease. ${ }^{45}$

Our enchantment with music means that it can be a very effective and memorable medium for distinguishing a product. Traders can create identities for their products by associating them with unique pieces of music, which are significant to listening consumers. "[W]e listen to music for the experience of its meaning, for what it 'says' to us ... [s]omehow, music expresses things, tells a story." 46 Traders can make use of musical arrangements that appeal to specific sectors of society. Such segmentation can be very effective: ${ }^{47}$

Listeners also turn to particular genres of music for their external meaning, their social symbolism.

What better way to indulge aristocratic pretensions than to strut about in time to a Haydn symphony? And what better way to assert independence from tyrannical parents than to bombard them with Megadeth?

However, several kinds of disorders can occur in the auditory system, such as deafness, ear infections and tinnitus. ${ }^{48}$ These can reduce or even eliminate consumers' ability to recognise sound marks. Yet this is no different from the sense of sight, by which traditional trade marks have successfully been recognised by consumers despite widespread eyesight deficiencies.

\section{Smell and taste}

Less research has been conducted on the senses of smell and taste. "[V]ision and hearing are like the two pampered daughters, whereas smell is the Cinderella of perception." 49 However, studies have shown that the sense of smell is less sensitive than vision or hearing.

44 R Jourdain Music, the Brain and Ecstasy: How Music Captures our Imagination (William Morrow \& Co, New York, 1997) 296.

45 Jourdain, above n 44, 301.

46 Jourdain, above n 44, 261.

47 Jourdain, above n 44, 262.

48 This is a high-pitched ringing in the ears that can be caused by a high fever, ear infection, or taking large doses of aspirin. Matlin, above n 41, 299.

49 Matlin, above $\mathrm{n} 41,370$. 
Unlike the receptors in vision, hearing, and the skin senses, smell has only one kind of receptor. ${ }^{50}$ There are also wide individual differences among people in their smell sensitivity.

The effectiveness of a scent mark will depend on the ability of consumers to satisfactorily distinguish between different smells. One study demonstrated that humans can distinguish a difference of 26 per cent or more in smells. ${ }^{51}$

The ability to detect a difference of $26 \%$ might sound reasonably sensitive until you compare the difference thresholds for smell with similar thresholds for other senses. For example, people can tell the difference between two sounds if they differ by as little as $0.3 \%$, a difference threshold roughly 100 times as sensitive. ${ }^{52}$

Another study ${ }^{53}$ involved presenting an odorant to participants, then several seconds later presenting a pair of odorants. The participants had to indicate which of the two odorants was "old" and which was "new". The accuracy was only about 70 per cent, which is "particularly dismal when that performance is compared with an accuracy of $99.7 \% 54$ for visual stimuli". 55

The sense of smell also involves the experience of adaptation. This is the temporary loss of sensitivity as a result of continued stimulation. A perfume, for example, seems to fade after a few minutes. ${ }^{56}$ This means that a smell, unlike a visual sign, cannot give a lasting impression. This may mean that a smell is less able to function as a memorable, distinguishing mark than signs identified by sight or hearing.

There is also a clear difference between the recollection and the recognition of smells. While a person may be able to remember and describe a smell that he or she has experienced,

50 Matlin, above $\mathrm{n} 41,374$. The author makes the interesting note that dogs have twenty times as many smell receptors as humans.

51 This was one study discussed by M M Mozell "Olfaction" in J W Kling \& L A Riggs (eds) Woodworth E Schlosberg's Experimental Psychology (3 ed, Holt, Rinehart \& Winston, New York, 1971).

52 Matlin, above $\mathrm{n} 41,379$.

53 T Engen \& B M Ross "Long-term Memory of Odors with and without Verbal Descriptions" (1973) 100 Journal of Experimental Psychology 221.

54 R N Shepard "Recognition Memory for Words, Sentences, and Pictures" (1967) 6 Journal of Verbal Learning and Verbal Behavior 156.

55 Matlin, above n 41, 383.

56 Matlin, above n 41, 379. 
the actual recognition of the scent as emanating from a particular source is unlikely. The fine gradations between scents are often difficult for the human nose to distinguish. ${ }^{57}$ Additionally, the "tip-of-the-nose" phenomenon ${ }^{58}$ shows that people often smell a scent and are certain that the smell is familiar, but cannot put a name to it. ${ }^{59}$

Smell is, unfortunately, less important in our thought processes than vision and hearing. ${ }^{60}$ This is demonstrated by our inability to accurately describe smells. "A sound, for example, can be precisely described as being a pure tone of $1000 \mathrm{~Hz}$ and $40 \mathrm{~dB}$. With odorants, we must settle for qualitative descriptions such as minty, goaty, and spicy." 61

Although the sense of smell is inferior to vision and hearing, it is much more sensitive and diverse than the sense of taste. Smell is actually a major component of our ability to distinguish one flavour from another. ${ }^{62}$ The sense of taste is, therefore, subject to the shortcomings of the sense of smell. It is also affected by several characteristics of the individual, such as smoking and insensitivity to certain substances. ${ }^{63}$

Taste, like smell, involves adaptation and difference thresholds that are less than impressive. The concentration of a substance must usually be increased by 15 to 25 per cent for a person to notice a difference in its taste. ${ }^{64}$

Therefore, while hearing is analogous to vision in being a fairly perceptive sense, smell and taste are much less sensitive. Marketers will certainly wish to tap into the phenomenon of sound marks, because language is the basis of human communication and "it is hard to think of any visual

57 H Burton "The UK Trade Marks Act 1994: An Invitation to an Olfactory Occasion" (1995) 17 EIPR 378, 380.

58 H T Lawless \& T Engen "Associations to Odors: Interference, Memories, and Verbal Labeling" (1977) 3 Journal of Experimental Psychology 52. This resembles the more familiar "tip-of-the-tongue" phenomenon.

59 Matlin, above n 41, 381.

60 Matlin, above $n$ 41, 370.

61 Matlin, above n 41, 371.

62 D Lyons "Sounds, Smells and Signs" (1994) 16 EIPR 540, 540.

63 Matlin, above n 41, 401.

64 Matlin, above n 41, 401. 
experience, artistic or otherwise, that is as overwhelming as music". 65 Although smell and taste are much less receptive senses, they can probably recognise scents and flavours that are strong and unique. Manufacturers should therefore also be eager to utilise very distinctive smells and tastes in order to distinguish their products in today's competitive and crowded marketplace.

\section{B Distinguishing a Product by an Association with its Source}

Sounds, smells and tastes are distinctive and perceptible features. This means that their use in relation to a product can serve to distinguish it. These signs can therefore serve to perform the basic function of a trade mark of distinguishing a product. For example, a distinctive sound or piece of music could be linked with a product in an advertisement. As consumers can competently perceive and remember sounds, this product is capable of being distinguished by its associated sign.

However, a trade mark must distinguish a product in such a way as to create a connection with the product's source. This association must be relevant to the consumer purchasing process because, "without consumer reliance, trade mark law would be pointless". 66 For a sound, smell or taste to truly act as a trade mark, consumers must have access to the mark, use that access in recognising the source of the product, and be capable of actually identifying the source by the mark. ${ }^{67}$

\section{Sounds}

A sound mark can either consist of the product's natural noise or an advertisement involving a piece of music or a distinctive sound. Either type of mark can be readily and accurately diffused to consumers by radio or television advertising. As the sense of hearing is quite perceptive, a sound mark stands a good chance of being remembered by consumers. A distinctive sound or an appealing musical arrangement could therefore be successfully linked with a product. The relative likelihood of consumers recalling a sound, in comparison to a scent or taste, means that exposure to a sound mark may well cause consumers to identify the product's source.

However, one must remember that "not all sounds distinguish source and most do not. In the case of musical sound, for example, the entertainment aspect generally overwhelms any

65 Jourdain, above n 44, 328.

66 Pickering, above n 4, 124.

67 Burton, above n 57, 379. 
other." ${ }^{68}$ Despite the perceptiveness of the sense of hearing, a sound mark will certainly have to be distinctive for consumers to actually associate it with its source. In theory, though, sounds are quite capable of performing the basic function of a trade mark, as advertising media make it easy for consumers to have access to a sound, and consumers are able to recognise a product's source by this access.

An example of a sound mark that is registered in New Zealand is the jingle for The Warehouse. ${ }^{69}$ This tune has become very distinctive because of its continuous use in the television and radio advertising for the stores. Most New Zealanders would almost instantaneously identify the origin of the product on hearing its sound mark. This jingle therefore performs the basic trade mark function of enabling consumers to ascertain the source of the advertised merchandise as The Warehouse.

\section{Smells}

Access to a scent mark would be most likely to occur after the product has been purchased. The smell may become familiar to consumers with their recurrent use of the product. However, a scent is less likely to be associated with the source of the product than a sound mark, because the sense of smell is relatively inferior. Consumers are less likely to accurately recall a particular smell when they are exposed to it for a second time.

A scent would have to be extremely unique, or uncommon in the context of a particular product, for it to be remarkable enough to become sufficiently familiar for a purchaser to think of it in connection with a source. ${ }^{70}$ It would then operate as a trade mark in the post-sale context. ${ }^{71}$

An example of this could be a licorice-scented furniture polish. If consumers purchased this product and were pleased with its cleaning power, they may recognise it in the future if they were subsequently exposed to its distinctive smell. The scent of this product would thus be functioning as a trade mark in the post-sale context, by conveying information about the

68 In re Paramount Pictures Corporation (1982) 213 USPQ 1111, 1113.

69 Trade mark number 252035, above n 26.

70 Burton, above $\mathrm{n} 57,379$.

71 Post-sale confusion was deemed to be relevant in New Zealand by Williams J in Levi Strauss \& Co v Kimbyr Investments [1994] 1 NZLR 332. 
product's characteristic of believed superior cleaning power, thus denoting its (albeit probably anonymous) source.

This example is feasible because a licorice scent is unique in respect of furniture polish. In contrast, consumers may not associate a lemon or pine scent of a furniture polish with its source, because these fragrances are more common in relation to household cleaning products. Due to the relative inferiority of the sense of smell, a fragrance will probably have to be quite extraordinary, either in the context of the product or as a newly created scent, to enable consumers to recognise the source of the product from which it emanates. However, such fragrances are certainly capable of functioning as trade marks in the post-sale context. As a scent mark would often be intended to last the lifetime of a product, the existence of this avenue may be important. ${ }^{72}$

\section{Tastes}

Consumers will usually only have access to a taste mark after the product has been purchased, because samples are generally not provided. Tastes may become familiar enough by the recurrent use of the good for consumers to associate them with the source of the product. Like smells, tastes are inherently less distinguishable than visual or aural features of a product, and are therefore less likely to be accurately remembered and associated with the product's origin.

A taste will probably have to be quite unique to the type of product for consumers to link it to the source of the good. Tastes will have to be perceived as being very different from those of substitute products before they will perform the function of enabling consumers to recognise the marks as originating from a particular source.

The natural taste of a product will not be able to function as a trade mark, because it will not be distinctive enough in the context of the type of good to allow consumers to identify the source. This may mean that tastes will seldom be registered as trade marks in relation to food because consumers are unlikely to demand foods flavoured with "unnatural" tastes.

Taste marks are more likely to be registered in respect of inedible goods. Such products may be tasted in practice, but do not require a flavour to perform their function. Examples of such products are postage stamps and envelopes, which are tasted when consumers lick them to activate their adhesive properties. These goods do not have a discernible natural taste, and

72 Burton, above n 57, 381. 
do not require a flavour in order to perform their function. This means that a manufacturer could add a flavour to the product that would be both desirable and distinctive to consumers. This taste could therefore be memorable enough for consumers to link it with the source of the product, thus performing the basic function of a trade mark.

\section{Trade Marks at the Point of Sale}

One of the main economic functions of trade marks is to reduce consumers' costs of acquiring information about products. "Consumers will search for the trade mark they desire rather than the desired characteristics of the product". ${ }^{73}$ The policy of trade marks must therefore require that consumers are able to use the mark to identify the source of the product at the point of sale. Although no such stipulation exists in the Trade Marks Act 1953, the whole economic rationale behind protecting trade marks (potentially indefinitely) is that they reduce consumer search costs by facilitating consumer recognition of a product in the marketplace. ${ }^{74}$ As consumers have become accustomed to identifying a product by reference to its trade mark, they must be able to rely on trade marks at the point of sale to locate a particular product from a desired source. ${ }^{75}$

If a registered trade mark cannot be used by consumers to identify the source of the product at the point of sale, protection is essentially being conferred for a clever marketing device. As consumers cannot rely on such a mark to locate a particular product, the manufacturer obtains the whole benefit of its registration as a trade mark. Protection may accrue indefinitely to the trade mark as an independent creation in its own right. Care should therefore be taken to ensure that sounds, smells and tastes are only registered as trade marks if they distinguish a product by creating an association with its source at the point of sale.

\section{Sounds}

If a product makes a distinctive sound, a consumer could theoretically test the sounds that each possible substitute product makes, in order to find the product with the specifically desired sound. Hence, the product's sound could properly act as a trade mark by distinguishing the good as originating from a particular source. Examples of such products are

73 Ministry of Commerce Review of Industrial Property Rights, Patents, Trade Marks, and Designs: Possible Options for Reform 2 (Wellington, 1990) 28.

74 Pickering, above n $4,88$.

75 Pickering, above n 4, 153. 
motorcycles, where a consumer could test out the sound of various engines, and "talking" dolls, where the sounds made by each are often the main selling point and are therefore readily accessible prior to sale.

However, such a trade mark arguably does not perform the economic functions of a trade mark, as the time-consuming nature of the task may mean that search costs are not reduced by the hastening of purchasing decisions. The sound would differ from visual trade marks, which can be identified and considered within a few seconds.

This kind of comparison of the sounds of products would also usually not be possible. Most products do not make a sound, let alone one that is distinctive from substitute goods. Retail situations such as Internet shopping may also not allow such testing of products (although Internet consumers could possibly download a demonstration of the sound).

Most importantly, consumers are unlikely to bother with such tests, especially if they find them embarrassingly conspicuous or time-consuming. Therefore, although consumers may have access to the mark, they may not use the mark to identify the source of the goods from which the sound emanates. Unless the sound forms an important part of the product, it is unlikely to be identified and relied on by consumers at the time of purchase, and is therefore unlikely to act as a trade mark in a pre-sale situation.

If the sound of a product is tested in order to ascertain preference, it is also not functioning as a trade mark. A consumer would then be selecting a good because of its pleasing sound, rather than selecting it because of its source, as indicated by the distinctive sound.

A noise or jingle used in the advertising of a product might also constitute a distinctive sound. Marketers may wish to register such sounds as trade marks, as their individuality makes them memorable to consumers. However, it is arguable that such sounds do not actively assist in consumer purchasing decisions. Although sounds used in advertising may make the product memorable to consumers, therefore distinguishing the product from its substitutes, the sound plays no part in identifying the desired product at the point of sale. Consumers will generally not hear an advertised jingle or noise at the point in time when they are trying to locate the desired product. Consumers will necessarily rely on visual elements of the product in order to identify it in the marketplace. While an advertised sound may have previously served to draw attention to the visual indicia attached to a product, the sound plays no part in assisting the consumer to actually select the desired product.

The Warehouse jingle is unlikely to function as a trade mark at the point of sale. Although the music is sufficiently familiar to many consumers to enable the source of the product to be 
identified, consumers cannot rely on it in order to locate the product at the point of sale. While the music may be played inside The Warehouse stores, consumers on the street cannot hear the jingle and thus cannot find the advertised store by its sound mark alone. Consumers instead rely on the visual features of the store, such as its distinctive large, red buildings, in order to find The Warehouse and its advertised goods.

Therefore, while an advertised sound may strengthen the brand of a product and be distinctive to that product, it cannot usually perform the trade mark's task of assisting consumer identification of the product at the point of sale.

The "Greensleeves" arrangement, on the other hand, is a rare example of a sound that does function as a trade mark at the point of sale. ${ }^{76} \mathrm{Mr}$ Whippy icecream vendors have played this music at the point of sale for years. Consumers readily identify the source of the product (the Mr Whippy brand of icecream vendor vans) simply by hearing the arrangement. Consumers, hearing the tune from inside their homes, decide to purchase an icecream from this familiar source. This example shows that, although it will be rare for a sound to function as a trade mark in a pre-sale context, it will certainly be possible.

\section{Smells}

The smell of a product may create problems in functioning as a trade mark. The first obstacle is the frequent lack of access to a product's smell at the point of sale. Fragrant products are usually packaged in a way that prevents their smell tainting other neighbouring products. Consequently, the smell may be barely discernible by consumers. A product's scent is therefore unlikely to assist a consumer in identifying the good at the point of sale.

Even if the scent of a product is detectable at the point of sale, a consumer is unlikely to rely on his or her sense of smell alone in identifying the source of a good. We generally rely on our sense of sight to identify products, whereas our sense of smell is more subjective. Visual features are more objectively obvious than a particular scent, from which people may detect different things. A person's sense of smell may also vary from one day to the next, due to allergies and sickness. The smell of a product is also more likely to change as it interacts with the smell of its surroundings. As a scent is inherently more subjective than a visual feature, it is unlikely to be relied on by consumers in making a purchasing decision.

76 Trade mark number 289083, above n 27. 
If the scent of a product, such as a perfume, is available for sample prior to the sale, the perfume will probably be purchased because of the scent alone. However, as the scent is not being used to indicate the source of the product, such a purchase will be made without the assistance of such an association. The scent will therefore not be functioning as a trade mark. ${ }^{77}$

Consumers are also unlikely to use their sense of smell to recognise a scent that has been described in the advertising of the product. Customers will almost always smell such a product to test if the scent is as good as it sounds, thus to ascertain their preference. The advertising is therefore unlikely to establish secondary meaning for a scent by creating an association between the mark and the source of the goods from which it emanates. ${ }^{78}$

Even if a product's scent becomes associated through practice with its origin, the product is still likely to be selected by reference to visual indicia, rather than by the association with its scent. Therefore, the fragrance still does not function on its own as a trade mark in the pre-sale context.

Manufacturers may use a smell to distinguish a product, enhance its appeal and brand value, and cause a consumer to make a repeat purchase. However, the scent may not be accessible at the point of sale and is unlikely to be relied on by consumers to locate a product from a particular source. The appeal of a fragrance will probably not suffice to overcome the problem of a general lack of reliance by consumers on their sense of smell. Scents are therefore unlikely to truly function in the trade mark sense. "[I]t cannot be ignored that the practice of 49 years bears out [the argument] that while fragrances fall within the framework of US trade mark law they fall foul of its substantive provisions". ${ }^{79}$

\section{Tastes}

Even stronger arguments can be made against the ability of tastes to act as trade marks. The most significant problem with a taste mark is that it cannot usually be experienced until it has ceased to be in the course of trade. This lack of access to the mark means that it cannot function as a trade mark in the pre-sale context. It is simply not socially acceptable (or legal) behaviour to taste products before they are purchased, unless samples are provided for this

77 Burton, above n 57, 379.

78 Burton, above n 57, 379 .

79 Burton, above $\mathrm{n}$ 57, 378. While scents have been registrable as trade marks under the Lanham Act since 1946, the first registration of a scent mark was in 1997. See In re Celia Clarke (19 September 1990) 429 TTAB, Number 758. 
purpose. Samples of a product are rarely available to consumers and, moreover, may not enable a consumer to conclude that the product is from a particular source if the unavailability of samples for substitute products does not allow a comparison to be made.

A person's sense of taste may also vary from one day to the next, and different people may detect different qualities from one particular flavour. The unreliability of this sense means that any pre-sale access to a taste mark may not even be used to identify the source of the goods.

The flavour may induce a consumer to make a repeat purchase of the product, but it usually cannot assist in the identification of the product in the marketplace. Consumers are also likely to buy a sampled product because of its flavour, not because the taste facilitated their identification of the particular desired source. In such a context, the taste would not be acting as a trade mark.

\section{Encroaching upon the Domain of Copyright}

\section{The different policies behind copyright and trade marks}

Unlike trade mark law, copyright protects a creation for its own intrinsic worth. ${ }^{80}$ The investment that has been put into a concept is rewarded through consequent protection of the finished product. However, trade marks are not protected for their own intrinsic worth. They are protected only insofar as they perform the additional function of distinguishing the product to which they are attached. Trade marks stem from a different branch of intellectual property rights than copyright. While copyright protects products in themselves, trade mark law only protects labels attaching to products.

Copyright and patents are therefore creatures of the law, brought into being with a specific purpose which may be defined in the abstract, whereas the trade mark is a creature of commerce and hence the reason for its protection may only be defined by reference to its function. ${ }^{81}$

As smells and tastes (and, to a lesser extent, sounds) are usually inherent features of goods, the protection conferred by trade mark registration would effectively apply to the whole product, rather than just to a label attached to a product. Protection that is analogous to

80 Pickering, above n 4, 116.

81 Pickering, above n 4, 34 . 
copyright would be achieved "by the back door". A scent or a taste is usually an "ornamental or functional feature of a product and therefore non-distinctive." 82

A primary scent is the fragrance that is emitted by a product as its primary purpose. Primary scents include perfumes, air fresheners and potpourri. Manufacturers of primary scented products would certainly want protection for the fragrance of their products, as the scent is the whole selling point and competitive advantage of the product. However, the fact that a scent is fundamental to the success of a product is no different from the success flowing from any other quality of a product. ${ }^{83}$ Just because something is commercially valuable does not make it registrable as a trade mark.

Trade mark protection is defined by reference to its function of allowing consumers to identify distinctive goods in the marketplace. If a smell that is basically the whole product is protected as a trade mark, the smell is effectively being protected as a property right itself. "A mark must be something distinct from the thing marked. A thing itself cannot be a mark of itself". ${ }^{84}$ In order to protect a primary scent, a sui generis right would need to be developed, overlying a rationale of protection analogous to copyright or patents. As trade mark law does not confer property rights per se, it is an inappropriate forum for seeking protection for such fragrances.

A product scent, in contrast to a primary scent, is a fragrance that is added to a product whose primary function is not to exude the scent. Product scents could perhaps be registrable as trade marks if they perform the requisite functions. However, these still encounter the problem that consumers are very unlikely to identify preferred fragrant products solely by their sense of smell.

Similarly, a substantial investment might be made in developing a new flavour to be used in sweets, for example. Such sweets would chiefly be purchased because of their flavour, as the principal purpose of eating sweets is to enjoy their taste. The manufacturer may well wish to protect its investment in creating the flavour, as its competitive advantage relies on producing a unique flavour of sweets. However, conferring trade mark protection on this new flavour would effectively create a property right in the type of sweets. A monopolistic situation would result, contrary to the economic purpose of trade marks of aiding

82 Burton, above n 57, 379.

83 Burton, above n 57, 379.

84 In re James's Trade Mark (1886) 33 Ch D 392 per Lindley LJ. 
competition. ${ }^{85}$ Consumers would not benefit from the conferral of protection for this trade mark, as they would be denied access to competitively priced substitute sweets, competitively branded substitute sweets, and possible future improvements on the flavour.

If the natural sound of a product could be registered as a trade mark, this would prevent competing marketers from demonstrating the similar sound of their products. This could create a species of monopoly on the sale of the type of product, especially if the sound is an important part of the product. For example, the sound of a car motor is a functional feature of a car. If an unusually noisy car motor could be registered as a trade mark, this could prevent competitors from entering any future niche market for noisy cars. Similarly, the attempt by Harley Davidson to register the sound of its motorcycle as a trade mark must fail for the reason that it is the natural sound of the particular type of product. ${ }^{86}$ Although the sound of a Harley Davidson motorcycle may well be distinctive and even unique, it is simply the natural sound of a V-twin, common crankpin motorcycle engine. The registration of such a sound as a trade mark would preclude any future competition in manufacturing motorcycles with V-twin, common crankpin engines.

Trade mark protection must be kept very separate from other intellectual property rights, such as copyright and patents, which protect creations in themselves. A registered trade mark confers potentially unlimited rights, unlike that provided by copyright or patents. This unlimited protection is justified by the requirement of "sustained investment and management in order to add value to the mark" and make it commercially useful. ${ }^{87}$

If a smell or a taste is inherently appealing, it is arguable that a trade mark consisting of such a smell or taste would not require continued investment after registration. There are a limited number of appealing tastes and smells, and their appeal is, by and large, physiologically determined. Consequently, trade marks registered in respect of appealing tastes and smells would give the owner a monopolistic use of an eternally appealing characteristic. The first person to register a very pleasing taste or smell in relation to a type of

85 It is important to note that trade marks do not facilitate perfect competition, as products are differentiated by features other than price. Rather, trade marks enable competition in the sense of responding to the reality of the contemporary marketplace, which requires various methods of product differentiation as a response to consumers' demands. See Pickering, above n 4, 82.

86 H-D Michigan Inc, serial number 74/485, 223.

87 Pickering, above n 4, 116. 
product may not have to continually invest in promoting the trade mark, if it is inherently appealing and memorable to consumers.

Perhaps this is not very different from a marketer creating an eye-catching design or shape for the packaging of a product. It is arguable that such radical packaging is inherently more likely to be noticed and remembered by consumers. However, there is a much more limited spectrum of appealing tastes and scents than there are of outstanding visual designs. The appeal of visual features is also perhaps less physiologically determined than the appeal of tastes and smells. Consumers are much more likely to be influenced in their consideration of the appeal of visual features by current fashion trends. Therefore, the registration of smells and tastes as trade marks is more liable to create monopolies over the use of inherently appealing features than the more common registrations of word and design marks. Such monopolies are not in the interests of consumers and do not accord with the underlying purpose of trade mark law of encouraging competition.

The United States courts have developed a theory of colour depletion in cases involving colour marks. Where there is an existing or potential competitive need to use colour within an industry, colour marks have not been protected. The effect of granting a colour mark must be carefully considered because its protection "will necessarily extend to confusingly similar shades. Given the fine gradations which use common elements, many shades will be encompassed within one mark." ${ }^{88}$ A similar theory could be applied to scent marks 89

The range of fragrances available for primary scents is limited by the requirement of a pleasant scent and it is a moot point how many genuinely new types of fragrance could be found which did not overlap existing ones. Thus if similar scents are monopolised only the mark owner could produce variations on a theme.

\section{Functionality}

There is a fundamental prohibition on registering descriptive marks because of the public interest in keeping trade descriptions in the public domain. ${ }^{90}$ Words cannot be registered as trade marks if they describe what a product is. ${ }^{91}$ Otherwise, competitors would not be able to

88 Burton, above n 57, 381.

89 Burton, above n 57, 381.

90 Pickering, above n 4, 11.

91 Pickering, above n 4, 11. 
use these essential words to describe their products and the trade mark owner would have an effective monopoly on marketing this type of product.

An analogy can be made with allowing a sound, smell or taste that is a functional feature of the product to become a registered trade mark. If the sound, smell or taste is an essential part of a product it should not be able to be registered as a trade mark. A popular perfume, for example, should not be registrable as a trade mark because the scent is the essence of the product. Yet the substantial investment that has been made in the perfume and its resulting commercial success mean that this is exactly the type of smell that producers will most want to protect.

United States courts have frequently applied the functionality doctrine to trade mark cases. Trade mark protection is not granted for a feature that contributes to or performs a function of the product. If trade mark protection were to be conferred for such a feature, others would be prevented from producing goods that require or perform the same function. ${ }^{92}$ A feature of goods is functional if it affects their purpose, action or performance, or the facility or economy of processing, handling or using them. ${ }^{93}$ The doctrine has been applied to both utilitarian and aesthetic features, although inconsistently in terms of the latter. ${ }^{94}$

The functionality doctrine has had limited relevance to trade mark law in New Zealand, because "traditional" trade marks, consisting of words, symbols or designs, are added to the exterior of the product rather than consisting of inherent features of the product. The only type of monopoly that is at risk of being created in these circumstances is the exclusive use of a word that is essential to describe the type of product. The possibility of this situation is adequately dealt with by the requirement in the Trade Marks Act 1953 that marks be distinctive. This specifically prohibits the registration of a mark consisting solely of a word or words having a direct reference "to the character or quality of the goods or services". 95

However, the Trade Marks Amendment Act 1999 did not modify this prohibition to enable it to literally apply to signs consisting of sounds, smells or tastes, which are sought to be registered as trade marks. Therefore, such applications could theoretically meet the

92 Burton, above $\mathrm{n} 57,382$.

93 Restatement of the Law, Torts, s 742.

94 C R Courtade "Application of Functionality Doctrine under $\S 43(A)$ of Lanham Act" (1986) 78 ALR Fed 712 .

95 Trade Marks Act 1953, s 14(1)(d). 
distinctiveness criterion without a consideration of whether the marks directly refer to the character or the quality of the goods from which they emanate. The sound of a Harley Davidson motorcycle engine could be considered distinctive, as no other motorcycle in the marketplace currently produces a similar sound, and would therefore be registrable as a trade mark under section 14(1)(e). ${ }^{96}$ This would create a monopoly in the manufacture of this type of motorcycle engine, thus barring any future direct competition.

Such monopolies may be created because of the Act's failure to assert that a sound, smell or taste mark is not distinctive if it directly refers to the character or quality of the goods. The functionality doctrine will consequently need to become much more relevant in New Zealand trade mark law, in preventing the natural sounds, smells and tastes of products being registered as trade marks.

Where "a feature is indispensable to the success of the product, it may be considered to perform an aesthetic function." 97 Primary scents, which are the product, and product scents that are added for the purpose of masking odours, fulfil utilitarian functions and could not be registered as trade marks. A scent may also be aesthetically functional if consumers specifically desire it in the product, regardless of the source. ${ }^{98}$ This could occur if a particular scent confers to the consumer a predisposed image, such as the image of a clean home that is conveyed by the pine or lemon scent often used in household cleaning products. ${ }^{99}$

Similarly, a flavour given to a pharmaceutical product would be functional "either because it is essential or very useful in masking the naturally unpalatable pharmaceutical preparation, or because its naturally unpalatable taste functions as a placebo."100 This conclusion is further supported by the practical problem of there being relatively few flavours that can be used to mask the natural taste of such a substance.

Smells and tastes are therefore unlikely ever to be non-functional features of a product. The underlying policy of trade marks requires that only signs that promote, rather than prevent,

96 It would be registrable as "[a]ny other distinctive sign".

97 Burton, above n 57, 382.

98 Burton, above n $57,382$.

99 F M Hammersley "The Smell of Success: Trade Dress Protection for Scent Marks" (1998) 2 MARQIPLR 105,136 .

100 N L Clarke "Issues in the Federal Registration of Flavors as Trademarks for Pharmaceutical Products" (1993) U Ill L Rev 105, 129. 
competition should be registrable. This necessitates the consistent use of the functionality doctrine, in the absence of an equivalent legislative provision, for all trade mark applications involving a sound, smell or taste. ${ }^{101}$

\section{A comparison with extended passing off}

There is an increasing acceptance that a creation is worthier of protection if a substantial investment has been made in it. ${ }^{102}$ This notion is evident in the recent expansion of the passing off action by the Australian courts to cover character merchandising misappropriation cases.

The elements of the tort of passing off are a misrepresentation made by a trader to prospective consumers which damages or is likely to damage the plaintiff's business or goodwill. Character merchandising is the use of the reputation or goodwill of a character, personality or institution to promote the sale of goods or services. In the Australian judiciary's struggle to prevent unauthorised character merchandising through the law of passing off, the basic ingredients of the tort have somewhat been lost sight of.

Recent Australian judgments have shown a tendency to overlook the requirement of a misrepresentation in favour of an element of misappropriation. ${ }^{103}$ An unauthorised association with a character, image or name has been found to be sufficient to constitute passing off. A misrepresentation to the public about the existence of a licensing arrangement in respect of the character, image or name has been readily inferred, on the assumption that the Australian public is generally aware of the practice of character merchandising agreements. This misrepresentation element has therefore become somewhat redundant and artificial.

101 A contrast can be made with the colour combinations that were the subject of Smith Kline E French Laboratories Ltd's Trade Mark Applications [1976] RPC 511. The colour that was added to the drug capsules in that case was not an inherent feature of the ingredients. Nor did it perform a utilitarian function, or an aesthetic function, by being essential to the success of the type of product. The drugs would be precisely as effective without the colour. The colour combinations properly acted as trade marks by serving to distinguish the drugs from those of other manufacturers. The popularity of the trade mark did not make it a functional feature.

102 Pickering, above n 4, 109.

103 For example, Paul Dundee v Koala Dundee Pty Ltd (1988) AIPC 90-527; Pacific Dunlop Ltd v Hogan (1989) ATPR 40-948; Twentieth Century Fox Film Corporation $\mathcal{E}$ Anor $v$ South Australian Brewing Co Ltd $\mathcal{E}$ Anor (1996) ATPR 41-483. 
The requirement of damage is also approaching mere formality status, as promotional goodwill, which is now protected by the extended tort of passing off, can be damaged simply by a lost opportunity to obtain sponsorship fees for the character merchandising. ${ }^{104}$

Passing off is arguably an inappropriate cause of action for character merchandising complaints. While the original passing off action punished traders for deceiving the public by making misrepresentations, character merchandising cases essentially entail complaints that images or characters have been misappropriated. The plaintiff is basically seeking affirmation that he or she owns the character or image that has allegedly been misappropriated. The remedy sought is a proprietary right in the character or image itself.

This is arguably an unacceptable leap for the law of passing off to take. Closely related to the law of trade marks, passing off stems from the branch of intellectual property that protects labels attaching to goods, rather than granting property rights in the labels per se.

It is important to note that the New Zealand courts have not yet recognised this extension of the tort of passing off. In Tot Toys Ltd $v$ Mitchell 105 Fisher J, whilst observing "[t]he desirability of consistency in commercial matters between two CER countries", 106 questioned the appropriateness of following Australian precedents that "force the square peg of character merchandising into the round hole of passing off". 107

Allowing the natural sounds, smells and tastes of goods to be registered as trade marks would similarly represent a leap into protecting the marks as property rights in themselves. These marks would no longer be defined by reference to their function of distinguishing goods, as they would essentially be goods in themselves.

The real problem in the primary scents market is that of protecting fragrances from being broken down and recreated. ${ }^{108}$ The search for a legal solution for the problem of free-riding essentially involves a claim for a copyright type of protection ${ }^{109}$

104 R G Howell "Personality Rights: A Canadian Perspective: Some Comparisons with Australia" (1990) 1 IPJ 212, 221.

105 Tot Toys Ltd $v$ Mitchell (1992) 4 NZBLC 102797.

106 Tot Toys Ltd $v$ Mitchell above n 105, 102827.

107 Tot Toys Ltd $v$ Mitchell above n 105, 102830.

108 Burton, above n 57, 384.

109 Burton, above n 57, 384. 
Competitors should be entitled to compete freely within that market producing variations on a theme, or even independently the same product, but they should not be allowed to do so on the backs of the research of others.

The policy of trade mark law means that it is unlikely that these primary scents will be registrable as marks, thus denying protection to the fragrances which are the most valuable. However, it is really not trade mark protection that is required. "Nobody's interests are served by the artificial squeezing of cases deserving of some form of protection into fields of law not tailored to a particular need." 110

If the extension of the passing off action were accepted in New Zealand, this could arguably lead the way for the analogous expansion of what is registrable as a trade mark. The respective subjects of protection, the goodwill and the trade mark, have both become very valuable as assets in themselves. This is evidenced by widespread valuations of goodwill and trade marks on company balance sheets. If a passing off action can in effect be used in a character merchandising case to obtain a proprietary right in an image itself, then perhaps a trade mark that basically comprises an entire product should also be registrable.

The natural law rule of protecting all products of intellectual efforts, labour and skill has traditionally been qualified by the common law. An additional economic or social justification is required before protection is granted. ${ }^{111}$ A trade mark must be capable of distinguishing a good or service before it is registrable. Otherwise, consumers would not receive the economic benefit conferred by such protection of a reduction in search costs due to their ability to rely on the mark to identify the product amongst its substitutes. Similarly, methods of treating human illness are not patentable, regardless of the amount of effort that has gone into their development. ${ }^{112}$ The underlying premise in such instances is that some appropriations are not harmful when balanced against the public interest.

One must hope that judicial sympathy for the investment that has been made in a scent or flavour that constitutes the essence of a product will not be allowed to override the traditional

110 Burton, above $\mathrm{n} 57,384$.

111 S Ricketson "Character Merchandising in Australia: Its Benefits and Burdens" (1990) 1 IPJ 191, 205.

112 Wellcome Foundation Ltd $v$ Commissioner of Patents [1983] NZLR 385. Note, however, that the actual substances used in the method of treatment are patentable: Pharmaceutical Management Agency Ltd $v$ Commissioner of Patents (1999) 6 NZBLC 102701. 
rationale for trade mark protection. While trade marks can indeed be extremely valuable assets, they should not be able to be protected for their own worth.

\section{REGISTRABILITY}

A sign can only be registered under the Trade Marks Act 1953 if it fits the definition of "trade mark". This means that the sign must be capable of being represented graphically and capable of distinguishing the goods or services of one person from those of another. ${ }^{113}$ A sign must also comply with the distinctiveness or capability of distinguishing requirement under section 14 or section 15 of the Act.

\section{A Distinctiveness or Capability of Distinguishing}

To be registrable in Part A of the Trade Marks Register, a sound, smell or taste needs to constitute a distinctive sign. ${ }^{114}$ To be registrable in Part B, it must be capable of distinguishing the applicant's goods or services from others in the market. ${ }^{115}$ IPONZ has developed specific criteria by which sound, smell and taste marks are examined to determine if they are distinctive or capable of distinguishing the related products. ${ }^{116}$

\section{Sound marks}

In examining applications involving sound marks, the complexity of the sound is considered. The more complex the sound, the more likely it will be deemed to be distinctive or capable of distinguishing. The rationale behind this consideration is that other traders may reasonably wish to incorporate simple sounds into their own sound marks. A simple piece of music consisting of three notes, for example, is unlikely to suffice, because its registration could impinge on the rights of other traders.

Sounds that are naturally associated with the goods or services in question are considered by IPONZ to be non-distinctive. The registration of such sounds would impede other traders who justifiably wish to use such sounds. An example of such a sound would be a popping cork in relation to champagne. Similarly, certain sounds are considered by IPONZ to be in the public domain and free for all traders to use. For example, the national anthem, or a piece of

\footnotetext{
113 Trade Marks Act 1953, s 2(1).

114 Trade Marks Act 1953, s 14(1)(e).

115 Trade Marks Act 1953, s 15(1).

116 Information obtained from Ainsley Thomson, Trade Marks Division, IPONZ, 8 August 2000.
} 
music associated with the specific trade, would not be deemed to be distinctive or capable of distinguishing the products in question.

\section{Scent and taste marks}

Applications for the registration of a scent or taste mark will not succeed if the smell or taste is an inherent or natural characteristic of the goods or services in question. The natural smells and tastes of products should be available for all traders to use.

A smell or taste will be deemed non-distinctive and incapable of distinguishing the goods or services if the use of the mark is common in the specific industry, or other traders in the industry would be likely to wish to use it in the ordinary course of their business. An example of such a smell is the lemon scent that is commonly used in washing detergent and laundry products.

IPONZ therefore appears to be conscious of the fact that caution is required before these new types of trade marks should be judged capable of distinguishing goods or services. Basic criteria have been developed to guard against the danger of deeming sound, smell and taste marks to be distinctive simply because there are no other registered marks with which to compare them.

\section{B Capable of Being Represented Graphically}

The requirement that a sign be capable of being represented graphically "appears to stem from a practical desire to allow a particular mark to be easily identified or searched by those who may be affected by the mark."117 By contrast, the desirability of the graphic representation clearly demonstrating the scope of the rights granted by registration is not the main purpose of the requirement. ${ }^{118}$ This may present problems in trade mark infringement actions because the graphic representation of the mark may not clearly establish the limits of the right granted.

In view of the primary purpose of allowing trade marks to be easily searched on the register, IPONZ requires that the sign is in fact represented graphically before it can be registered.

117 Potter, above n 21, 228.

118 Potter, above n 21, 228. 


\section{Sound marks}

It is generally accepted that a picture, drawing, or even a written description may constitute a graphic representation of a mark. ${ }^{119}$ Several trade marks have been registered in New Zealand and overseas, containing simple written descriptions of the sign. For example, the Unilever PLC "squeak" trade mark is defined as "a squeak produced by the friction of the thumb or forefinger on dishware." 120 This appears to be a fairly narrow and confined definition of the extent of the mark, as only one type of sound can presumably be made by such friction on dishware. In contrast, trade marks have been registered in the United States with written descriptions that are perhaps less clearly defined. NBC's Chime Mark, which was issued on 13 July 1971, was described in its application as comprising: ${ }^{121}$

[A] sequence of chimelike musical notes which in the key of $C$ sound the notes $G, E, C$, the ' $G$ ' being the one just below middle $C$, the ' $E$ ' the one just above middle $C$, and the ' $C$ ' being middle $C$, thereby to identify applicant's broadcasting service.

It is arguable that "chimelike musical notes" can encompass a range of sounds, according to different sized chimes and the ability of synthesizers to imitate chimes, both poorly and admirably. The musical arrangement embodied in this mark is also very common, as it comprises the standard base triad (albeit inverted) of the simplest major scale. The fact that no rhythm is given to the three notes also means that the scope of the trade mark right is probably quite a lot broader than the applicant's actual use of the sound.

Another example from the United States is the trade mark registration number 922585, which was issued on 19 October 1971 to Broadcast Plaza Incorporated. This mark is defined as "a sound mark consisting of three short pulses followed by a longer pulse". ${ }^{122}$ The term "pulse" is not defined. It could theoretically be construed as referring to the timing of the beats, as opposed to the type of sound created. If this were the case, any type of instrument that was used to produce four sounds of any pitch could possibly be held to infringe this trade mark right, as long as the first three sounds were short and the fourth was long.

119 Potter, above n 21, 230.

120 Trade mark number 247094, above n 25.

121 N Rubner-Fransen "Ambience, Subliminal Confusion, Color, Smell, and Sound: The Protection of NonVerbal Rights under the Trademark and Unfair Competition Law" (1991) C674 Ali-Aba 155, 186.

122 Rubner-Fransen, above n 121, 186. 
As New Zealand will be looking to such foreign jurisdictions as the United States in the attempt to align our trade mark registration system, such broadly defined trade marks may cause IPONZ to be fairly relaxed in its determination of what constitutes a sufficient graphic representation. ${ }^{123}$

Thus it appears that a sound will be sufficiently graphically represented by submitting a musical score, a list of the notes used in an arrangement, or just a written description of the type of sound. As applications for sound marks begin to be made, it is unlikely that many will be declined because of an insufficient graphic representation. Complaints about the ambiguity of written descriptions may not surface until the trade marks register becomes more crowded with widely defined sound marks.

\section{Scent marks}

The only scent mark that has been registered in the United States is that of Celia Clarke. The Trademark Trial and Appeal Board on 19 September 1990 ruled that the scented fragrance of sewing thread and embroidery yarn is capable of serving as a trademark to identify and distinguish the product. ${ }^{124}$ The application for the registration of the mark described it as "a high impact, fresh, floral fragrance reminiscent of Plumeria blossoms." 125

The description of this fragrance certainly appears to be sufficiently vivid to ensure that its trade mark right is clearly defined. In New Zealand, such a description might well suffice to constitute a graphic representation of the mark. However, the fact that this scent appears to be the first in its field to be applied to yarn and thread products must surely influence the extent of the description required by registering authorities. If no other similar trade marks have

123 This argument is more compelling when one considers that the United States trade mark registration system is based on samples, with the main purpose being the clear demarcation of the rights conferred by a trade mark registration. In contrast, the New Zealand system of mere graphic representation would presumably require a less clearly defined sign, in order to satisfy the main purpose of allowing searchers to identify a registered mark.

124 In re Celia Clarke, above $\mathrm{n} 79$.

125 Although the United States system of trade mark registration involves depositing samples, as opposed to the New Zealand system of submitting graphic representations, Clarke's sample consisted of a "drawing" involving only this description. Clarke's written description of her mark is therefore relevant to deciding if it would suffice as a graphic representation in New Zealand. 
been registered, IPONZ may well be satisfied with such a representation consisting of four adjectives. ${ }^{126}$

Clarke may be wrongly decided or it may prove that the test of validity will be applied less stringently when there is slim chance of a future demand for competition using fragrances in a given market.

It is arguable that such an application in New Zealand would not even need such a lucid representation. For a product that is unique in its use of this type of mark, and one that would have the first registered scent mark, just the words "floral fragrance" may suffice. These words would graphically represent the mark, albeit broadly, and the mark would be capable of distinguishing the yarn from other types of yarn.

Indeed, such a broad description would fulfil the trade mark register's primary objective of allowing the type of mark to be easily identified by searchers. A potential competitor would know from this description that another floral scented yarn on the market would be likely to infringe this registered trade mark. However, the exact likelihood of infringement would not be determinable because the fragrance is not explicitly described on the register. Yet this is not the register's primary purpose. The main purpose, to allow the trade mark to be easily identified, would still be achieved, because the potential competitor would know that it would be on shaky ground if it produced an alternative floral scented yarn. This would have been the case even if the more detailed description had been filed. After all, one flower may well smell like another, and confusion would definitely be possible if there were both Plumeria-scented and rose-scented yarns on the market.

Despite the apparent comprehensiveness of the description of Clarke's mark, it is difficult to see what the words "high impact" and "fresh" add to the depiction of the fragrance. What is to be compared with this scent so that it is deemed to be of high impact? Is a contrast to be made with other, unscented yarns? Or is this fragrance high impact in relation to actual Plumeria blossoms? The inclusion of this adjective seems strange because Clarke's advertisements of her product referred to it as "soft-scented". ${ }^{127}$ Furthermore, the smell of flowers is surely always fresh, as old flowers actually lose their scent. The words "reminiscent of" serve to cloud the scope of the scent mark, as the smell of any flower could potentially be seen as reminiscent of Plumeria blossoms.

126 Burton, above $\mathrm{n} 57,380$.

127 "Trademarks: TTAB Rules that Fragrance Mark is Registrable for Scented Yarn" 41 PTCJ 123, 123. 
The analysis of written descriptions as graphically representing scents indicates that they are unsatisfactory in clearly depicting the smell one would expect to experience. One can only get a very general idea of the type of smell registered. A layperson has a "poor capability of linking smell with language."128 While a written representation should serve to fulfil the register's main objective of allowing searchers to identify the trade mark, potential competitors will really be left in the dark as to whether a similar mark will infringe the trade mark right.

Due to the inherent unreliability of a human's sense of smell, it is perhaps acceptable to have a broadly defined scent mark. After all, even if a narrow description of a scent were filed, other fragrances that do not correspond to this description may still infringe the trade mark if there is a likelihood of confusion. ${ }^{129}$ Perhaps it is preferable to have broadly defined representations to deter competitors producing goods with fragrances that are slightly similar, as they could infringe the trade mark.

There is a well-established methodology that standardises lists of terms to characterise sensory perceptions, that has been used by various workers. ${ }^{130}$ For example, the Schutz classification system lists nine classes of odorants: etherish, spicy, fragrant, sweet, burnt, sulfurous, oily, rancid and metallic. There are also sophisticated systems for measuring perceptions of smell intensity.

Fragrances can be analysed by gas chromatography or high-performance liquid chromatography, which are separation methods that provide qualitative and quantitative information about complex mixtures. The resultant chromatogram is a plot of the amount of a compound against the time taken for its separation. ${ }^{131}$ Such instrumental methods are usually used in conjunction with a sensory evaluation called an "aromagram", in order to build up an information profile about a smell that takes account of both the concentrations of each compound and the distinctiveness of the odour. ${ }^{132}$

\footnotetext{
128 Burton, above n 57, 379.

129 Infringement can occur by the use of a similar sign in respect of similar or identical goods or services, if such use is likely to deceive or cause confusion. Trade Marks Act 1953, ss 8(1A)(c) and 9(2).

130 Lyons, above n 62, 540.

131 Lyons, above n 62, 541.

132 Lyons, above n 62, 542.
} 
Chromatograms and "aromagrams" may also be able to give a sophisticated graphic representation of a scent without giving away its chemical composition. This avoids the risk of anyone counterfeiting the manufacturer's fragrance. ${ }^{133}$ However, the chromatography methods do not chemically identify the active, sensorially important components. There is no absolute assurance that two mixtures that produce the same chromatogram will smell the same.

Although there are several methods for graphically representing a scent mark, none can provide an unambiguous depiction of the exact fragrance or a clear scope within which competition would be judged infringement. "[I]n the final analysis sensory evaluation is ultimately subjective and presents obvious problems for a trade mark system which must delimit exclusive rights." 134 Yet this should not prevent the deeming of a scent as sufficiently graphically represented because the primary objective of the register enabling searchers to easily locate a mark is served by a fairly broad description.

\section{Taste marks}

Taste is the only sign for which applicants have not yet sought trade mark registration. ${ }^{135}$ Taste is similar to smell, in terms of being intangible and difficult to precisely describe. Therefore, a written description of a taste should likewise suffice as a graphic representation for the purposes of the Act. Tastes, like smells, can also be graphically represented by more sophisticated methodologies. ${ }^{136}$

Similar problems apply to the identification of the scope of the right granted by the registration of a taste mark. Words can only give the gist of a flavour. For example, cherry flavoured sweets often taste very dissimilar to the fruits they are supposed to represent. Such sweets often taste very scented and more like soap than cherries.

The limits of the trade mark right represented by a written description of a taste will, therefore, not be known until an infringement action is taken. However, the main objective of allowing a searcher to easily identify a particular taste mark will be achieved by a graphic representation consisting of a written description.

133 Lyons, above n 62, 543.

134 Lyons, above n 62, 541.

135 Clarke, above n 100, 108.

136 Lyons, above n 62, 540. 
The subjectivity of taste is perhaps even more pronounced than that of smell. The huge variance in people's likes and dislikes in food shows that not everyone has the same, or even a similar, experience of a flavour. As taste buds also largely rely on one's sense of smell, the interplay of these two variable senses reinforces this subjectivity. ${ }^{137}$

Perhaps a broadly defined graphic representation of a taste would best fulfil the objective of enabling searchers to identify marks. The inherent subjectivity of the sense of taste means that the risk of confusion by similar tastes is quite high. Therefore, a competitor should know that it would be on shaky ground if it were to manufacture even a slightly similar-tasting product.

\section{INFRINGEMENT}

The right conferred by the registration of a trade mark will be infringed if any person, not being the proprietor or a registered user, uses in the course of trade an identical sign in relation to any goods or services that are identical with those in respect of which the trade mark is registered. ${ }^{138}$ Infringement will also occur if an identical sign is used in relation to similar goods or services, or a similar sign is used in relation to identical or similar goods or services, if the use is likely to deceive or cause confusion. ${ }^{139}$

\section{A What is an Identical Sign?}

A registered trade mark is defined by the words appearing on the trade marks register. ${ }^{140}$ This means that a sign is identical to a registered trade mark if it comes within its graphic representation.

The scope of a sound, scent or taste mark may not be easily ascertainable from the register. Unlike the more simple word or design marks, which can be precisely represented, most graphic representations of scents, tastes and sounds will only give a vague impression of the extent of the trade mark right. Written descriptions of scents and flavours will be quite ambiguous, as adjectives cannot suitably depict signs that are perceived by the more subjective

\footnotetext{
137 Lyons, above n 62, 540.

138 Trade Marks Act 1953, s 8 (1A)(a).

139 Trade Marks Act 1953, ss 8 (1A)(b) and (c).

140 Levi Strauss \& Co v Kimbyr Investments, above n 71, 360.
} 
and variable senses of smell and taste. The same is true for sounds that cannot be represented by musical notation, such as a cock's crow.

As the Registrar of Trade Marks is content to accept graphic representations consisting of simple descriptions of sound, smell and taste marks, it is likely that most applicants will choose this method, due to the relative ease of composing a written description compared to formulating a chromatogram or another sophisticated method.

The use of words to graphically represent sounds, smells and tastes will necessarily be broad, in order to try to convey the essence of the particular mark through this fairly unsuitable medium. Many similar sounds, scents or tastes will fall within a broad description of such a mark, and will therefore be legally identical to the mark.

\section{B What is a Similar Sign?}

If a sound, smell or taste does not fall within the graphic representation of a registered mark, it will not be identical. The owner of the registered mark will then have to prove that the competing sound, smell or taste is a similar sign. The inquiry of whether a sign is similar to a registered mark will probably be incorporated in the narrower issue of whether or not the sign is likely to deceive or cause confusion. A court is unlikely to find that a sign is not similar to a registered mark if it has found that its use is likely to deceive or cause confusion.

\section{What is Likely to Deceive or Cause Confusion?}

Unless an identical sign has been used in relation to identical goods or services, infringement is not automatic. The court will need to find that the use of the defendant's mark is likely to deceive or cause confusion.

"The tests to be applied in deciding whether there is confusing similarity are well established ... [t] he plaintiff's mark as registered must be compared with the defendant's mark as it appears in actual use."141 However, the novelty of sound, smell and taste marks means that it is unclear exactly how such tests are to be applied in cases involving these marks.

\section{Sound marks}

Confusion may be relatively straightforward to determine in the case of a sound mark consisting of music, because both the mark and the alleged infringing sign may be able to be compared in terms of the melodic and rhythmic aspects of their notation. Other distinctive

141 Levi Strauss \& Co v Kimbyr Investments, above n 71, 363. 
noises may also be fairly simple to compare. The sense of hearing is quite perceptive, and, despite the common occurrence of partial hearing loss, most people will probably agree on whether or not a sound is so similar to the trade mark as to be likely to deceive or cause confusion.

However, sounds will be more difficult to compare than traditional word or design marks. A sound does not leave a lasting visual impression on those exposed to it, unlike the more conventional marks. The listener's impression of the mark will ultimately be subjective. This may mean that confusion is more likely because of the inability to visually compare signs. Moreover, one's visual perception of an object is probably superior to one's sense of hearing. This is especially relevant in today's marketplace, as the expansion of branding has meant that consumers have learnt to strongly rely on the visual features of a product in order to distinguish it instantly from its substitutes.

\section{Scent and taste marks}

It will be more difficult to determine if the use of a smell or taste that is similar to a registered mark is likely to deceive or cause confusion. The senses of smell and taste are certainly inferior to the senses of hearing and sight. A less distinct impression is taken from a smell or taste than is taken from a visual or aural experience. Smells and tastes are, therefore, inherently less memorable and less easy to accurately compare. The inability to accurately recognise or even recollect a smell or taste means that its confusion with another smell or taste is quite likely. One can foresee consumers who have experienced a floral scented product mistaking a fruity scented product for it in the future. As one's perceptions of smell and taste are quite limited, especially in retrospect, a consumer may remember little more about such a product than his or her enjoyment of the sweet smell. Confusion may occur, therefore, despite the argument that a floral scent is not inherently very similar to a fruity scent.

Confusion regarding a scent or taste mark will be rare prior to the product's sale because consumers are unlikely to have access to the mark at this time. Packaging and the frequent inability to sample a product bearing a scent or taste mark before it is purchased mean that consumers are not exposed to the smells or tastes by which they could be confused.

If it is possible to sample the products before they are bought, confusion is unlikely to occur unless the scents or tastes are very similar. Although smell and taste are the least perceptive of the senses, a consumer will remember the impact of a smell or taste that has just been sampled. If all such products are tried, the impact of each taste or smell will last long enough to enable a fairly accurate comparison to be made. Any confusion that occurs in this situation is likely to 
be the result of a very similar smell or taste to the registered mark. If this is the case, infringement will (and should) be found, because the defendant's sign is deceptive.

Yet confusion may also result in this situation if consumers do not sample the product bearing the registered mark because they believe that they have already found the desired mark in their sample of the alleged infringing product, and thus need search no further. However, this circumstance would involve a comparison being made of the defendant's mark with the consumer's limited memory of the previously experienced scent or taste. This could result in confusion even though the scents or tastes are not very similar in fact.

Even if samples are available at the point of sale, it is unlikely that consumers will rely solely on their senses of taste or smell to select a desired product. Consumers are accustomed to recognising products by visual aspects of their trade dress. It is much more likely that consumers will search for desired products by their senses of sight than their senses of smell or taste, as it is more reliable and enables almost instant recognition. This means that a consumer who experiences a product containing a pleasing smell or taste will probably make a point of remembering its visual appearance in order to recognise it in the future. This probable lack of reliance on scent or taste, as opposed to sight, when selecting goods means that consumers are unlikely to be confused about a product's source because of its scent or taste. Visual aspects of the alleged infringing product will almost always obviate any possible confusion caused by a similar, or apparently similar, smell or taste. Post-sale confusion will, therefore, be more relevant to the infringement of scent and taste marks. ${ }^{142}$

The imperfect recollection and recognition of smells and tastes mean that confusion is much more likely than it would be for visual features. The subjectivity of the impact of smells and tastes, especially when these senses are affected by sickness or allergies, means that it will be extremely difficult for a court to determine whether there is an objective likelihood of confusion between two smells or tastes.

142 Confusion can be caused by the use of the marked product after its sale: Levi Strauss \& Co v Kimbyr Investments, above $\mathrm{n} 71$. 
Such a determination may be aided by the introduction of survey evidence. ${ }^{143}$ A survey should allow for the imperfect recollection of scents and flavours by exposing participants to the defendant's mark only after sufficient time has elapsed since they were exposed to the plaintiff's mark. However, even with such evidence available, in the final analysis "it is for the court to decide the question as a matter of personal impression having due regard to the evidence which has been produced." ${ }^{144}$

The ultimate subjectivity of judgments is inherent in our legal system. However, if a case alleging infringement of a smell or taste mark is decided without the benefit of survey evidence, the result is entirely dependent on the judges' subjective comparison of the two marks in question. Such a decision is arguably more fraught with subjectivity than a case involving word or design marks, because a comparison of smells or tastes is inherently more subjective than one's perception of visual features. A comparison made by a court between two scents or flavours is also unlikely to involve the time delay required to adequately assess post-sale confusion. This means that the imperfect recollection and recognition of scents and tastes by consumers, which will arguably be the principal contributor to post-sale confusion, will not be taken into account. While this may mean that scents or tastes that are, on their face, quite dissimilar are not found to be likely to deceive or cause confusion, the statutory infringement provision is not truly complied with. ${ }^{145}$

\section{The Likelihood of Infringement}

The requirement that a mark be capable of graphic representation appears to be fairly lenient, as it is probably satisfied in the case of a complex scent mark by a brief written

143 Williams J noted the two essential requirements of an admissible survey, referring to the judgment of Barker J in Auckland Regional Authority v Mutual Rental Cars (Auckland Airport) Ltd [1987] 2 NZLR 647. The interviewees must be selected so as to represent a cross-section of the relevant public, and the precise instructions to the interviewers as to how they were to carry out the survey must be disclosed. If a survey is admissible, Williams J observed that the value of the answers and the weight to be accorded to them depends on the structural integrity and fairness of the survey questionnaire and its individual questions. See Levi Strauss \& Co v Kimbyr Investments, above n 71, 364.

144 Levi Strauss \& Co v Kimbyr Investments, above n 71, 363.

145 Courts can consider the imperfect recollection of consumers in determining whether or not the registration of a mark would be likely to deceive or cause confusion, thus causing it to be unregistrable under s 16 of the Act. See Pioneer Hi-Bred Corn Company $v$ Hy-Line Chicks Pty Ltd [1978] 2 NZLR 50, 5354 per Richmond P. Courts should similarly consider consumers' imperfect recollection in determining whether or not the use of a mark is likely to cause confusion in an infringement action. 
description. This means that the scope of the trade mark right is uncertain from its representation on the register. In addition to this, the subjectivity of the impact of sounds, smells and tastes means that it is unclear how the courts will approach the question of the likelihood of confusion. There is also a very limited range of pleasant but distinctive fragrances and flavours that could be applied to a product. Accordingly, a competitor is unlikely to manufacture a mark that is at all similar to one that is already registered.

The type of smell or taste most likely to be registrable as a trade mark is one which is very unusual in relation to the type of product. An example of this would be strawberry scented motor oil, in respect of which the scent is distinctive given that other motor oils do not smell at all fruity. Registrable marks will need to be specially developed in order to be added to the core products, as the natural smells of goods are unlikely to be registrable as trade marks. In view of this, a manufacturer will not waste resources on creating such a scent or taste if it could be held to infringe a previously registered mark.

The unusual categories of scents and tastes on the trade marks register are, therefore, unlikely to become crowded. Whilst their addition to the list of registrable signs accords with allowing anything that can distinguish goods or services to be registrable as a trade mark, it is clear that smells and tastes do not always easily fit with the pro-competitive policy of trade mark law.

\section{CONCLUSION}

The Trade Marks Amendment Act 1999 was not meant to produce any substantial changes to the law of trade marks in New Zealand. The main alterations transpired in the provision made for collective trade marks. While the extension of the definition of "sign" to specifically include sounds, smells and tastes hardly received a mention by Parliament in its discussion of the Bill, these new types of trade marks actually raise several novel issues. Such marks are fundamentally different in nature from the more traditional word and design trade marks. Rather than being perceived visually, these new marks rely on the senses of hearing, smell and taste, with which consumers are relatively unaccustomed to using in their identification of different products in the marketplace.

As the senses of hearing, smell and taste are arguably inferior to the sense of sight, trade marks consisting of sounds, smells and tastes will be less able to distinguish the goods to which they are attached. Consumers may also be less likely to rely on these inferior senses in locating a desired product in the marketplace. Signs that are not relied on by consumers at the point of sale cannot truly act as trade marks. Sound, smell and taste marks that are identified 
by consumers prior to their purchases must also facilitate quick recognition of the marked products amongst their substitutes. If this does not occur, the economic function of trade marks, to reduce consumer search costs, is not achieved.

The policy behind trade marks is to protect signs that distinguish products by indicating their source, in the interests of benefiting consumers whose search costs are reduced by their reliance on such signs. There is a real danger that this policy could be overridden by affording trade mark protection to signs that are essentially the whole product. As the natural sounds, smells and tastes of products are often their main selling point, manufacturers will probably seek to register these as trade marks. However, such a registration would create a monopoly on the manufacture of that type of product, which is quite contrary to the rationale behind trade mark protection.

Basic registration criteria have been developed to take account of some of the new issues raised by the possibility of sound, smell and taste marks. IPONZ will not regard a mark as distinctive or capable of distinguishing if it is currently used, or will foreseeably be used in the future, by other traders in the industry. However, no consideration appears to be made of whether or not the sound, smell or taste will act as a trade mark at the point of sale.

The requirement that marks be graphically represented will be satisfied by a written description of the sound, smell or taste, even though words are generally unsatisfactory in unambiguously depicting these signs. More sophisticated methodologies, such as musical notation or chromatograms, can also be used.

Issues will also arise in relation to alleged infringements of sound, smell and taste marks. Sounds, smells and tastes may be held to be identical to registered marks that are graphically represented by the use of broad written descriptions. The inherent subjectivity and unreliability of the senses of smell and taste may also mean that confusion between two fairly dissimilar scents or flavours is foreseeable. However, the predicted lack of reliance on the senses of smell and taste in consumer decision making may mean that confusion is actually quite unlikely to occur.

The future resolution of the issues that spring from the introduction of sound, scent and taste marks is certainly something to look forward to. The Legislature predicted that the registration of these new types of trade marks would indeed make the intellectual property 
world "a lot more interesting", 146 but perhaps never foresaw the diversity of the associated issues that would surface.

146 (5 October 1999) 580 NZPD 19610 